Received: 2014.12.25

Accepted: 2015.03.02

Published: 2015.06.25

Authors' Contribution:

Study Design A

Data Collection B

Statistical Analysis C

Data Interpretation D

Manuscript Preparation E

Literature Search F

Funds Collection G

Corresponding Author:

Source of support:

Background:

Material/Methods:

Results:

Conclusions:

MeSH Keywords:

Full-text PDF:

\title{
Relation of Serum and Vitreous Concentrations of Fetuin-A with Diabetic Retinopathy
}

BC 1 Chunming Zhao*

DEF 1 Jiangping Hou*

DF 2 Shengxi Wang

AG 2 Rui Jiang
1 Department of Ophthalmology, Provincial Hospital Affiliated to Shandong University, Jinan, Shandong, P.R. China

2 Department of Oncology, Provincial Hospital Affiliated to Shandong University, Jinan, Shandong, P.R. China

* These two authors contribute equally to this article

Rui Jiang, e-mail: sljrui@126.com

Natural Science Fund Project in Shandong Province (ZR2013HQ031)

Fetuin-A, a liver-derived glycoprotein, is correlated with diabetes. The aim of the present investigation was to evaluate serum and vitreous concentrations of fetuin-A in patients with diabetic retinopathy (DR).

We randomly selected 224 diabetic patients and 68 control subjects for this study.

There were markedly higher serum and vitreous fetuin-A concentrations in proliferative diabetic retinopathy (PDR) patients than in the other three groups. NPDR patients exhibited elevated vitreous fetuin-A concentrations compared with patients without DR. However, no significant differences in serum fetuin-A concentrations were observed between NPDR patients and patients without DR. In addition, there were significantly lower concentrations of serum and vitreous fetuin-A in control subjects compared with the other three groups.

The occurrence and severity of DR is correlated with serum and vitreous fetuin-A concentrations.

alpha-2-HS-Glycoprotein • Angiogenesis Inducing Agents • Diabetic Retinopathy

http://www.medscimonit.com/abstract/index/idArt/893403

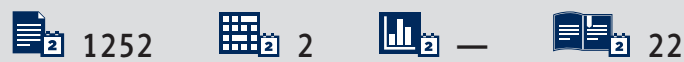




\section{Background}

Diabetic retinopathy (DR), a serious complication of diabetes mellitus, is characterized by epiretinal outgrowth of fibrovascular membranes at the vitreoretinal interface [1]. The prevalence of blindness resulting from DR is estimated as more than 10000 individuals each year [2]. The pathogenesis of DR is complicated, and many inflammatory cytokines are involved in the process. Much evidence indicates that chronic low-grade inflammation is involved in the pathogenesis of diabetic retinopathy [3].

Fetuin-A is a glycoprotein exclusively produced in the liver and then secreted into circulation in high concentrations [4]. It has been shown to inhibit insulin action at the step of the insulin receptor tyrosine kinase in rodents [5]. In addition, fetuin-A knockout mice showed improved insulin sensitivity and were resistant to weight gain after being fed a high-fat diet compared with wild-type controls [6]. Patients with type 2 diabetes mellitus (T2DM) had higher fetuin-A levels than healthy controls [7]. These data indicate the role of fetuin-A in the development of insulin resistance and diabetes.

The relationship between fetuin-A and DR has not been investigated to date. Therefore, the aims of the present investigation were to assess circulating and vitreous concentrations of fetuin-A in patients with DR and to compare results with the controls.

\section{Material and Methods}

\section{Study population}

This study consisted of 224 patients with T2DM who underwent vitreoretinal surgery for prolonged vitreous hemorrhage and tractional retinal detachment involving macular lesions. T2DM was diagnosed according to the American Diabetic Association criteria with a fasting glucose level $\geq 7.0 \mathrm{mmol} / \mathrm{L}$ or 2-hour postprandial plasma glucose level $\geq 11.1 \mathrm{mmol} / \mathrm{L}$. All patients were evaluated by biomicroscopy using a fundus contact lens and gonioscopy with a slit-lamp. The severity of diabetic retinopathy was graded according to the international clinical classification of diabetic retinopathy [8]: diabetic patients without DR: No abnormalities; non-proliferative diabetic retinopathy (NPDR): microaneurysms, intraretinal hemorrhages, definite venous beading, or prominent intraretinal microvascular abnormalities, and no signs of proliferative retinopathy; proliferative diabetic retinopathy (PDR): neovascularization, vitreous/preretinal hemorrhage. Based on that classification, these patients were then divided into three groups: 68 diabetic patients without DR, 54 patients with PDR, and 102 patients with NPDR. Exclusion criteria included the following: previous vitrectomy, other ocular disorders such as uveitis, glaucoma and corneal neovascularization, other systemic diseases including heart failure, renal failure, hematologic, cardiologic, and metabolic disorders other than diabetes, photocoagulation, and intra-vitreal hemorrhages during the past three months. The control group comprised 68 patients matched for age, sex, and body mass index (BMI) who underwent vitrectomy for retinal detachment. These patients were determined to be without systemic disease, including diabetes.

The study was approved by the university ethics board and all patients provided written informed consent.

\section{Laboratory methods}

Vitreous samples were obtained by manual suction into a syringe through the aspiration line of vitrectomy, before the infusion line was opened. Blood samples were collected and the vitreous samples were immediately centrifuged for 10 minutes at $4^{\circ} \mathrm{C}$ at $3000 \mathrm{rpm}$. The serum and vitreous samples were analyzed for fetuin-A using commercially available enzyme-linked immunosorbent assay (R\&D Systems Inc., Minneapolis, MN, USA).

\section{Statistical analysis}

The results are displayed as means \pm standard errors (interquartile range). Comparisons of the characteristics between control subjects, diabetic patients without DR, NPDR patients, and PDR were performed by chi-square tests, one-way ANOVA, or KruskalWallis test. All analyses reported significance at the $P<0.05$ level.

\section{Results}

\section{Baseline parameters}

There were increased systolic blood pressure (SBP), fasting plasma glucose (FPG), HbA1c, and triglycerides (TG), low-density lipoprotein cholesterol (LDL-C), as well as reduced highdensity lipoprotein cholesterol (HDL-C) in T2DM patients compared with the controls (Table 1).

\section{Serum and vitreous fetuin-A}

As displayed in Table 2, there were markedly higher serum and vitreous fetuin-A concentrations in proliferative diabetic retinopathy (PDR) patients than in the other three groups. NPDR patients exhibited higher vitreous fetuin-A concentrations compared with patients without DR. However, no significant differences in serum fetuin-A levels were observed between NPDR patients and patients without DR. In addition, there were significantly lower concentrations of serum and vitreous fetuin-A 
Table 1. Various characteristics of diabetic patients and controls.

\begin{tabular}{|c|c|c|c|c|c|}
\hline & \multirow{2}{*}{ Controls } & \multicolumn{3}{|c|}{ Diabetic patients } & \multirow{2}{*}{$P$} \\
\hline & & Without DR & NPDR & PDR & \\
\hline $\mathrm{N}$ & 68 & 68 & 54 & 102 & \\
\hline Age (years) & $56.60 \pm 9.34$ & $57.49 \pm 11.18$ & $57.76 \pm 8.96$ & $57.12 \pm 11.42$ & 0.934 \\
\hline Gender (M/F) & $32 / 36$ & $39 / 29$ & $27 / 27$ & $56 / 46$ & 0.612 \\
\hline $\mathrm{BMI}\left(\mathrm{Kg} / \mathrm{m}^{2}\right)$ & $25.68 \pm 1.91$ & $25.96 \pm 4.44$ & $26.63 \pm 3.41$ & $26.35 \pm 4.03$ & 0.471 \\
\hline $\mathrm{SBP}(\mathrm{mmHg})$ & $122.28 \pm 12.60$ & $137.21 \pm 24.12^{*}$ & $141.39 \pm 24.98^{*}$ & $142.22 \pm 24.84^{\star}$ & $<0.001$ \\
\hline $\mathrm{DBP}(\mathrm{mmHg})$ & $76.53 \pm 8.41$ & $83.53 \pm 19.38^{\star}$ & $81.30 \pm 15.15$ & $84.32 \pm 13.98^{\star}$ & 0.006 \\
\hline $\mathrm{FPG}(\mathrm{mmol} / \mathrm{L})$ & $5.09 \pm 0.43$ & $8.26 \pm 1.70^{\star}$ & $8.34 \pm 1.52^{*}$ & $8.33 \pm 1.76^{\star}$ & $<0.001$ \\
\hline HbA1c (\%) & $5.08 \pm 0.73$ & $7.79 \pm 1.32^{*}$ & $7.86 \pm 1.36^{\star}$ & $8.08 \pm 1.28^{*}$ & $<0.001$ \\
\hline $\mathrm{TC}(\mathrm{mmol} / \mathrm{L})$ & $4.93 \pm 0.80$ & $5.22 \pm 1.20$ & $5.14 \pm 1.04$ & $5.18 \pm 1.03$ & 0.348 \\
\hline TG (mmol/L) & $1.09 \pm 0.35$ & $1.87 \pm 0.62^{*}$ & $1.71 \pm 0.51^{*}$ & $2.00 \pm 0.68^{*}$ & $<0.001$ \\
\hline LDL-C (mmol/L) & $3.13 \pm 0.68$ & $3.49 \pm 0.98^{*}$ & $3.50 \pm 0.95^{*}$ & $3.47 \pm 0.86^{*}$ & 0.038 \\
\hline HDL-C (mmol/L) & $1.45 \pm 0.28$ & $1.15 \pm 0.25^{*}$ & $1.10 \pm 0.20^{*}$ & $1.09 \pm 0.21^{*}$ & $<0.001$ \\
\hline
\end{tabular}

${ }^{*} P<0.05$ vs. control.

Table 2. Serum and vitreous fetuin-A levels in controls, diabetic patients without DR, NPDR patients, and PDR patients.

\begin{tabular}{|c|c|c|c|c|c|}
\hline $\begin{array}{l}\text { Fetuin-A } \\
\text { (ng/mL) }\end{array}$ & $\begin{array}{l}\text { Controls } \\
(n=68)\end{array}$ & $\begin{array}{l}\text { Without DR } \\
\quad(n=68)\end{array}$ & $\begin{array}{l}\text { NPDR } \\
(n=54)\end{array}$ & $\begin{array}{c}\text { PDR } \\
(n=102)\end{array}$ & $P$ value \\
\hline Serum & $\begin{array}{c}262.17 \\
(196.22-316.02)^{\star *, \star * *}\end{array}$ & $\begin{array}{c}289.43 \\
(236.79-341.18)^{\star}\end{array}$ & $\begin{array}{c}310.52 \\
(243.78-361.98)^{\star}\end{array}$ & $\begin{array}{c}345.79 \\
(297.35-379.76)^{\star, \star \star, * \star *}\end{array}$ & $<0.001$ \\
\hline Vitreous & $\begin{array}{c}87.29 \\
(70.89-107.22)^{\star \star, \star * *}\end{array}$ & $\begin{array}{c}99.46 \\
(85.86-115.24)^{*}\end{array}$ & $\begin{array}{c}108.24 \\
(93.99-133.33)^{\star, * *}\end{array}$ & $\begin{array}{c}134.26 \\
(110.12-152.40)^{\star, * \star, * * *}\end{array}$ & $<0.001$ \\
\hline
\end{tabular}

${ }^{*} P<0.05$ vs. control; ${ }^{* *} P<0.05$ vs. diabetic patients without $D R ;{ }^{* * *} P<0.05$ vs. NPDR patients.

in control subjects compared with diabetic patients without DR, NPDR patients, and PDR patients.

\section{Discussion}

Fetuin-A, a $60 \mathrm{kDa}$ glycoprotein, is produced exclusively by the liver. Fetuin-A is an endogenous natural inhibitor of insulin receptor tyrosine kinase [9]. In comparison to wild-type mice, fetuin-null mice demonstrated a lower fasting insulin resistance index, significantly lower blood glucose and insulin levels, and improved insulin sensitivity [10]. Furthermore, compared to wild-type mice, fetuin-null mice demonstrated increased skeletal muscle and liver insulin receptor autophosphorylation [10]. Fetuin-A decreased skeletal muscle glucose uptake by downregulating Akt and subsequent glucose transporter type 4 (GLUT-4) translocation to the plasma membrane [11]. These findings point to the promoting role of fetuin-A in diabetes. Serum fetuin-A concentrations were higher in an impaired glucose tolerance group than in a normal glucose tolerance group [7]. Plasma fetuin-A levels were positively associated with diabetes risk after adjustment [12]. Newly diagnosed type 2 diabetes patients showed higher serum fetuin-A levels than healthy controls [7]. These findings indicate that fetuinA may be involved in the pathogenesis of diabetes.

Fetuin-A is known to inhibit ectopic calcium deposition and protect from vascular calcification. Fetuin-A is correlated with macrovascular disease of diabetes [13]. Fetuin-A levels were significantly lower in T2DM patients with calcified plaques than in those without calcified plaques [14]. Eraso et al. reported that lower level of circulating fetuin-A was associated with peripheral arterial disease in T2DM beyond traditional and novel cardiovascular risk factors [15]. Another study demonstrated that serum fetuin-A levels are independently correlated with the presence and severity of coronary artery disease (CAD) in T2DM patients [16]. 
Fetuin-A was also demonstrated to be associated with microvascular complications of diabetes. Serum levels of fetuin-A were significantly higher among T2DM patients with diabetic nephropathy (DN) when compared to those with normoalbuminuria [17]. Fetuin-A levels in T2DM patients with microalbuminuria were determined to be lower than in those with macroalbuminuria [18]. Urinary excretion of fetuin-A significantly increased during the progression of albuminuria and glomerular filtration rate (GFR) stages [19]. Fetuin-A has been demonstrated to be a risk factor for both microalbuminuria and reduction of GFR in DN [19]. DR is another microvascular complication of diabetes. The results of the present study show elevated serum and vitreous fetuin-A levels in DR patients compared with the controls. Jung et al. reported that mean serum fetuin-A levels were not significantly different between T2DM patients with and without DR [20]. These conflicting data may be due to disease progression differences, different populations or assays applied, or incomplete control for confounding variables.

Angiogenesis plays a key role in the mechanism of DR. A variety of angiogenic factors, among which vascular endothelial

\section{References:}

1. Fong DS, Aiello LP, Ferris FL III, Klein R: Diabetic retinopathy. Diabetes Care, 2004; 27: 2540-53

2. El-Asrar AM, Nawaz MI, Kangave D et al: High-mobility group box-1 and biomarkers of inflammation in the vitreous from patients with proliferative diabetic retinopathy. Mol Vis, 2011; 17: 1829-38

3. El-Asrar AM: Role of inflammation in the pathogenesis of diabetic retinopathy. Middle East Afr J Ophthalmol, 2012; 19: 70-74

4. Denecke B, Gräber S, Schäfer C et al: Tissue distribution and activity testing suggest a similar but not identical function of fetuin-B and fetuin-A. Biochem J, 2003; 376: 135-45

5. Mathews ST, Chellam N, Srinivas PR et al: Alpha2-HSG, a specific inhibitor of insulin receptor autophosphorylation, interacts with the insulin receptor. Mol Cell Endocrinol, 2000; 164: 87-98

6. Mathews ST, Singh GP, Ranalletta $M$ et al: Improved insulin sensitivity and resistance to weight gain in mice null for the Ahsg gene. Diabetes, 2002 51: 2450-58

7. Ou HY, Yang YC, Wu HT et al: Serum fetuin-A concentrations are elevated in subjects with impaired glucose tolerance and newly diagnosed type 2 diabetes. Clin Endocrinol (Oxf), 2011; 75: 450-55

8. Wilkinson CP, Ferris FL III, Klein RE et al.; Global Diabetic Retinopathy Project Group: Proposed international clinical diabetic retinopathy and diabetic macular edema disease severity scales. Ophthalmology, 2003; 110: 1677-82

9. Rauth G, Pöschke O, Fink E et al: The nucleotide and partial amino acid sequences of rat fetuin. Identity with the natural tyrosine kinase inhibitor of the rat insulin receptor. Eur J Biochem, 1992; 204: 523-29

10. Mathews ST, Rakhade S, Zhou X et al: Fetuin-null mice are protected against obesity and insulin resistance associated with aging. Biochem Biophys Res Commun, 2006; 350: 437-43

11. Malin SK, Mulya A, Fealy CE et al: Fetuin-A is linked to improved glucose tolerance after short-term exercise training in nonalcoholic fatty liver disease. J Appl Physiol (1985), 2013; 115: 988-94 growth factor (VEGF) is the most important, are involved in the pathogenesis of DR. Fetuin-A was demonstrated to cause a significant stimulation of interleukin-6 (IL-6) and IL-8, as well as VEGF mRNA expression in both perivascular fat cells and endothelial cells [21]. This suggests that fetuin-A is an angiogenic mediator and plays an important promoting role in the development of DR through the angiogenic effects.

Vitreous fetuin-A concentrations are lower compared with serum fetuin-A concentrations, which suggests that vitreous fetuin-A may partly come from the bleeding of the vascular system of the eyes. In addition, fetuin has been found in retinal tissues [22]. Thus, vitreous fetuin-A may partly come from the retinal tissues. Fetuin- $A$ in eyes may promote DR development. Therefore, increased vitreous fetuin-A concentrations in DR patients may explain the presence and progression of $D R$.

\section{Conclusions}

Serum and vitreous fetuin-A concentrations are correlated with the occurrence and disease progression of DR.

12. Stefan N, Fritsche A, Weikert $C$ et al: Plasma fetuin-A levels and the risk of type 2 diabetes. Diabetes, 2008; 57: 2762-67

13. Schafer C, Heiss A, Schwarz A et al: The serum protein alpha 2-HeremansSchmid glycoprotein/fetuin-A is a systemically acting inhibitor of ectopic calcification. J Clin Invest, 2003; 112: 357-66

14. Emoto $M$, Mori $K$, Lee $E$ et al: Fetuin-A and atherosclerotic calcified plaque in patients with type 2 diabetes mellitus. Metabolism, 2010; 59: 873-78

15. Eraso LH, Ginwala N, Qasim AN et al: Association of lower plasma fetuina levels with peripheral arterial disease in type 2 diabetes. Diabetes Care, 2010; 33: 408-10

16. Zhao ZW, Lin CG, Wu LZ et al: Serum fetuin-A levels are associated with the presence and severity of coronary artery disease in patients with type 2 diabetes. Biomarkers, 2013; 18: 160-64

17. Mehrotra R, Westenfeld R, Christenson $P$ et al: Serum fetuin-A in nondialyzed patients with diabetic nephropathy: relationship with coronary artery calcification. Kidney Int, 2005; 67: 1070-77

18. Koluman BU, Mutluay R, Derici UB et al: Association between osteoprotegerin, fetuin-A, carotid intima media thickness, and urinary albumin excretion in Type 2 diabetes. Clin Nephrol, 2013; 80: 9-16

19. Inoue K, Wada J, Eguchi J et al: Urinary fetuin-A is a novel marker for diabetic nephropathy in type 2 diabetes identified by lectin microarray. PLoS One, 2013; 8: e77118

20. Jung $\mathrm{CH}$, Kim BY, Kim CH et al: Associations of serum fetuin-A levels with insulin resistance and vascular complications in patients with type 2 diabetes. Diab Vasc Dis Res, 2013; 10: 459-67

21. Siegel-Axel DI, Ullrich S, Stefan N et al: Fetuin-A influences vascular cell growth and production of proinflammatory and angiogenic proteins by human perivascular fat cells. Diabetologia, 2014; 57: 1057-66

22. Sheedlo HJ, Krishnamoorthy RS, Nelson TS et al: Retina-derived fetuin (RDF): analysis by immunocytochemistry, reverse transcriptase-polymerase chain reaction and Southern blot. Curr Eye Res, 1999; 19: 465-71 